\title{
Testosterone Levels and Development of the Penile Spines and Testicular Tissue during the Postnatal Growth in Wistar Rats
}

\author{
Marcela Arteaga Silva ${ }^{1 *}$, Rosa M. Vigueras Villaseñor ${ }^{2}$, Socorro Retana Márquez, \\ Marisela Hernández González ${ }^{3}$, Herlinda Bonilla Jaime ${ }^{1}$, Xochitl Guzmán García ${ }^{4}$, \\ José Luis Contreras Montiel ${ }^{1}$ \\ ${ }^{1}$ Department of Biology of Reproduction, Metropolitan Autonomous University, Iztapalapa, México \\ ${ }^{2}$ Laboratory of Reproductive Biology, National Institute of Pediatrics, México City, México \\ ${ }^{3}$ Institute of Neuroscience, University of Guadalajara, Jalisco, México \\ ${ }^{4}$ Department of Hydrobiology, Metropolitan Autonomous University, Iztapalapa, México \\ Email: *asm@xanum.uam.mx
}

Received May 10, 2013; revised June 10, 2013; accepted June 18, 2013

Copyright (C) 2013 Marcela Arteaga Silva et al. This is an open access article distributed under the Creative Commons Attribution License, which permits unrestricted use, distribution, and reproduction in any medium, provided the original work is properly cited.

\begin{abstract}
Aim of Study: Gonadal hormones exert a profound influence on the development, structure and function of the sexual organs. The testosterone is one of the androgens that plays an essential role in the development of sexual organs in male mammals. Therefore, the present study was undertaken to evaluate the testosterone levels and developmental pattern of the penile spines and seminiferous tubules during early postnatal life of Wistar rats. Methods and Materials: At 7, 14, $21,28,35,42,49,56,63$ and 70 days after birth, penile and testicular tissues of male rats were dissected out and fixed for histological study and plasma testosterone levels were determined using high resolution chromatography. Results: An increase in the number of penile follicles, primarily in the distal region of the penis, was observed from postnatal days 14 to 42, followed by a gradual decrease. Penile spines were absent from birth until the first growth peak, which was observed at 42 postnatal days. Both testicular weight and the area of seminiferous tubules showed gradual increases before achieving their highest values at 42 postnatal days. Similarly, a gradual increase in testosterone levels was detected from day 28, with a peak at 42 postnatal days. Conclusions: These data show a temporal association between the development of the penile spines and testicular tissue with gradual increases in testosterone levels. These results may contribute to a better understanding of the behavioral, hormonal and morphological changes underlying sexual maturation in male rats.
\end{abstract}

Keywords: Testosterone; Penile Spines; Testicular Tissue; Postnatal Growth; Male Rat

\section{Introduction}

Gonadal hormones exert a profound influence on the development, structure and function of the sexual organs. Several studies have established that the sexual organs of male mammals follow a specific pattern of postnatal developmental [1-5] which is easily affected by castration or hormonal alterations.

The role of androgens in the development of male reproductive organs is well documented [1]. One of the androgens that plays an essential role in the development of sexual organs is testosterone, which influences several

\footnotetext{
"Corresponding author.
}

organs, including the epididymis, the ductus deferens, the seminal vesicles, the prostate gland, and the penis $[1,6,7]$. In rats, alterations in androgenic activity during development can drastically affect not only the weight and size of the testes and the accessory sex organs (such as the prostate gland and the seminal vesicles), but also the timing of the balano-preputial separation (BPS) [8,9], the production of spermatozoa [10-12], and the protrusion of penile spines [13], among other aspects.

The penile spines are cone-like keratinized projections, cornified structures found circumferentially around the penile skin [14-18] of some mammals, including rodents, carnivores and primates. In rats, two principal functions 
have been proposed for these keratinized projections: 1) to stimulate the vagina during copulation and promote the neuroendocrine processes that result in ovulation and/ or the progestational state; and 2) to help males remove plugs that they, or other males, deposited during previous ejaculations, thereby promoting the fertility of the subsequent ejaculate $[19,20]$. Although the development pattern of the penile spines is not known, it has been suggested that these keratinized structures follow a peripubertal development pattern because they are androgen-sensitive [21,22]. The hormonal dependence of these structures has been demonstrated by means of castration (which triggers the regression and disorganization of penile spines at a moderately fast rate) [23], and hormonal restitution with androgens reverses the effect of the castration $[21,24,25]$.

A critical dependence on the androgens has also been described for the adequate development of the testes and the numerous seminiferous tubules they contain. The testes play a fundamental role in spermatogenesis, defined as the sequence of cytological events that result in the formation of mature spermatozoa from precursor cells [26]. It has been demonstrated that the development of testicular tissue follows a specific growth pattern in germinal cells with characteristic changes in the epithelium of the seminiferous tubules and an increase in the number of Leydig cells in the interstitium [5]. The progressive differentiation of the seminiferous tubules during early life is characterized by Leydig cells that acquire a steroidogenic organelle structure and enzyme activities metabolizing most testosterone a capacity that increases at 90 days in rats [3].

Several studies of penile spines have been conducted, all of which have focused mainly on morphological descriptions [27], hormonal regulation [15,17,21], or quantitative analyses after sexual experience [16], at specific ages of the adult rat. In relation to testicular morphology, numerous quantitative studies have been made in both adult rats $[28,29]$ during this rodent's postnatal development in order to study changes in the seminiferous tubules spermatogenesis $[30,31]$ and the interstitium of the testes [32].

However, there is relatively little information on the growth pattern of these sexual organs and their association with testosterone levels in early postnatal life. An extended study is needed to establish a more comprehensive understanding of the relationship between testosterone levels and the growth of these sexual organs, and to obtain a more complete explanation of the sexual maturation processes of the male rat. The purpose of this research, therefore, was to determine the development pattern of the penile epithelium and testicular tissues and to document changes in testosterone levels during the postnatal development of the male rat.

\section{Materials and Methods}

\subsection{Animals}

A total of 120 male Wistar rats (Rattus novergicus) were obtained from a colony bred by Harlan Laboratories at the Universidad Autónoma Metropolitana. They were maintained under a 14-hour light/10-hour dark cycle, with lights off at 1800 hours and temperature maintained at $20^{\circ} \mathrm{C} \pm 1{ }^{\circ} \mathrm{C}$, with access to food (Purina ${ }^{\circledR}$ rat chow) and water ad libitum. They mated and their progeny were used as subjects in this study. Weaning occurred on day 22 (day of birth $=1$ ), after which the animals were sexed and housed in plastic cages in groups of eight male rats from at least four different litters. All animals were humanely treated following the ethical principles and specified regulations as stated in the Official Mexican Norm NOM-062-200-1999 entitled "Specifications for the production, care and use of laboratory animals", and the Standard Guidelines set forth in the NIH Guide for the Care and Use of Laboratory Animals. All the male pup rats were randomly distributed into 10 groups of 12 animals each one according to age: 7, 14, 21, 28, 35, 42, 49, 56,63 and 70 days after birth.

\subsection{Plasma Collection and Testosterone Quantification}

The male rats of each age group were weighed, and blood samples were collected by cardiac puncture from deeply-anesthetized animals with sodium pentobarbital (ip, $100 \mathrm{mg} / \mathrm{Kg}$; Pfizer) at 7, 14, 21 and 28 days postpartum or by decapitation (after 35 days postpartum), during the dark phase (between 12:00 $\mathrm{h}$ and 13:00 $\mathrm{h}$ to prevent circadian fluctuations). The interval between the first and last subject sampled was approximately $10 \mathrm{~min}$. Plasma was obtained by centrifugation at $1500 \mathrm{rpm}$ for $30 \mathrm{~min}$. Testosterone was extracted from the plasma and quantified by HPLC with ultraviolet (UV) detection, using a modification of a procedure described elsewhere [33] Briefly, $100 \mu \mathrm{l}$ of a 19 -nortestosterone solution $(5 \mu \mathrm{g} / \mathrm{ml}$ in methanol) were added as an internal standard to $500 \mu \mathrm{l}$ of plasma. Testosterone was extracted by agitation with 5 $\mathrm{ml}$ of a diethyl ether-dichloromethane mixture (60:40 $\mathrm{v} / \mathrm{v}$ ), followed by centrifugation. One $\mathrm{ml}$ of HPLC degree water was added to the organic phase and centrifuged. The organic phase $(3 \mathrm{ml})$ was then evaporated under nitrogen at room temperature. The residue was dissolved in $100 \mu \mathrm{l}$ of a methanol-water mixture $(60: 40 \mathrm{v} / \mathrm{v})$. The HPLC column and pre-column (Waters Corp., Milford, MA) were equilibrated with a water-acetonitrile (65:35 $\mathrm{v} / \mathrm{v}$ ) mixture at a flow rate of $0.4 \mathrm{ml} / \mathrm{min}$. Testosterone separation was carried out at $40^{\circ} \mathrm{C}$. A system controller (Waters, 600-MS) was used to pump the mobile phase, and testosterone was identified by a UV detector (Waters, Mod. 486) at a wavelength of $250 \mathrm{~nm}$. Results were ana- 
lyzed by a data-handling station (Waters, Millennium 32 Workstation). The detection limit of the assay for testosterone was $0.05 \mathrm{ng} / \mathrm{ml}$ at a signal-to-noise ratio of $2: 1$. The average recovery of steroids after extraction from blood was approximately $85 \%$. The intra- and inter-assay variation coefficients for steroid determinations were $2.93 \%$ and $7.12 \%$, respectively.

\subsection{Collection and Processing of Penile and Testicular Tissues}

After blood collection, and at the different days of postnatal life, the animals were placed in a supine position with their penises completely protruded. Then $1 \mathrm{ml}$ of a $4 \%$ paraformaldehyde solution was injected through the penile vein until the organ appeared erect [19]. It was then cut and post-fixed by immersion in $10 \mathrm{ml}$ of the same fixative solution for $24 \mathrm{~h}$. The testes were fixed immediately by immersion in $4 \%$ paraformaldehyde for $24 \mathrm{~h}$. These tissues were then dehydrated, processed and embedded in paraffin. Longitudinal serial sections $(5 \mu \mathrm{m})$ were obtained from each penis, and transversal serial sections from each testis. Both kinds of tissue were stained with hematoxylin-eosin.

\subsection{Histological Analysis}

About 15-to-30 longitudinal sections of the midline portion of the penis were examined under a BX 51 Olympus light microscope (Tokyo, Japan) at $10 \times$ and $60 \times$ magnification. The formation of penile follicles (PF) was identified as dermic papillae, and the number of penile spines (PS) was determined by their cone-like, keratinized structure. Both structures were counted over a length of 0.2-to- $0.9 \mathrm{~mm}$ that included the proximal and distal regions of the penis. The morphometric properties of the seminiferous tubules were examined and analyzed at the midline portion of the testes. Histological analysis of the seminiferous tubules was performed using fifteen to thirty transverse sections of the seminiferous tubules per animal. The area of seminiferous epithelium was determined by subtracting the internal area from the external area using an image analysis system (Image-Pro plus 5.1, Media Cybernetics, Bethesda, MD, USA).

\subsection{Statistical Analysis}

For each parameter, the mean and SD for each experimental group were calculated. Comparisons of body weight, penile and testes weight, area and diameter of the seminiferous tubules, testosterone plasma levels, and number of penile follicles and spines in the proximal and distal regions of the penis were all performed with a one-way ANOVA, followed by post-hoc Tukey tests. All analyses were conducted with the GB-stat program probability test (School Park Dynamic Microsystems, Inc. 2000). A value of $p<0.05$ was considered statistically significant.

\section{Results}

\subsection{Body, Testes Weight and Area of Seminiferous Tubules}

Body weight increased significantly with the days of life of the male rat pups $[\mathrm{F}(9,110)=7839.84, \mathrm{p}<0.001]$. The average body weight at day 7 was $13.45 \pm 1.51 \mathrm{~g}$, and increased by 10-to-15 g per week. As Table 1 shows, the largest increase in body weight was recorded between 42 and 70 days of life ( $p<0.01$, respectively). The weight of the testes also showed a gradual increase with higher age $[\mathrm{F}(9.110)=5637.65, \mathrm{p}<0.001]$. Mean testes weight at day 7 was $0.033 \pm 0.004$, and the most pronounced growth was observed after 42 days, with the highest values reached at 70 days (Table 1).

\subsection{Testosterone Plasma Levels}

The different plasma levels of testosterone measured in relation to the age of the male rats are shown in Figure 1.

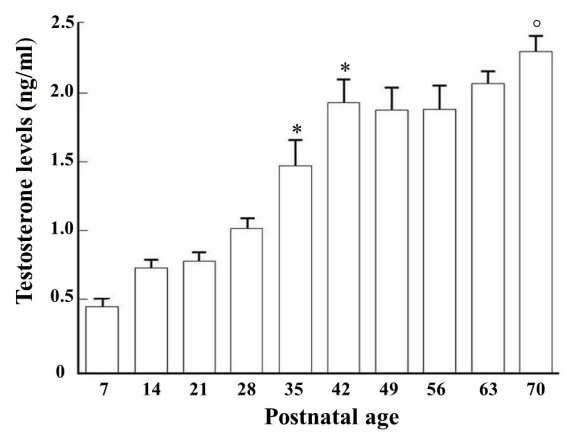

Figure 1. Testosterone levels $(\mathrm{ng} / \mathrm{ml})$ measured from 7 - 70 days of postnatal age in male rats. "p $<0.01$ compared to 7 th postnatal day. Compared to 42, 35, 28, 21, 14 and 7 days of postnatal age (ANOVA, followed by Tukey exact probability test).

Table 1. Parameters evaluated at different postnatal days in male Wistar rats.

\begin{tabular}{cccc}
\hline Age & $\begin{array}{c}\text { Body } \\
\text { Weight (G) }\end{array}$ & $\begin{array}{c}\text { Testicular } \\
\text { Weight }(\mathbf{G})\end{array}$ & $\begin{array}{c}\text { Area of Seminiferous } \\
\text { Tubules }\left(\boldsymbol{\mu \mathbf { M } ^ { 2 } )}\right.\end{array}$ \\
\hline $\mathbf{7}$ & $13.45 \pm 1.51^{*}$ & $0.033 \pm 0.004^{*}$ & $2075.72 \pm 41.55^{*}$ \\
$\mathbf{1 4}$ & $30.39 \pm 2.30$ & $0.056 \pm 0.007$ & $2241.29 \pm 28.03$ \\
$\mathbf{2 1}$ & $48.07 \pm 1.52$ & $0.132 \pm 0.004$ & $9059.15 \pm 1358.71$ \\
$\mathbf{2 8}$ & $55.45 \pm 2.02$ & $0.159 \pm 0.008$ & $13119.99 \pm 829.03$ \\
$\mathbf{3 5}$ & $65.05 \pm 2.00$ & $0.264 \pm 0.009$ & $16379.94 \pm 451.94$ \\
$\mathbf{4 2}$ & $89.83 \pm 3.01$ & $0.795 \pm 0.008$ & $34152.55 \pm 734.48$ \\
$\mathbf{4 9}$ & $123.75 \pm 1.41$ & $0.980 \pm 0.013$ & $35662.02 \pm 1146.62$ \\
$\mathbf{5 6}$ & $171.58 \pm 7.47$ & $1.210 \pm 0.025$ & $42184.29 \pm 1224.99$ \\
$\mathbf{6 3}$ & $256.11 \pm 10.66$ & $1.370 \pm 0.019$ & $51363.41 \pm 1599.63$ \\
$\mathbf{7 0}$ & $287.50 \pm 15.86$ & $1.570 \pm 0.048$ & $52351.30 \pm 1685.51$ \\
\hline
\end{tabular}

Data represented as mean $\pm \mathrm{SD}$. ${ }^{*}$ Indicates significant differences $(\mathrm{p}<0.01)$ between 7 days and the other postnatal days. 
The lowest level of testosterone was obtained at 7 days $(0.492 \pm 0.069 \mathrm{ng} / \mathrm{ml})$, but increased gradually from $14-$ to-28 days of age $[\mathrm{F}(9.110)=52.253, \mathrm{p}<0.001]$, exhibiting maximum levels at $35(1.50 \pm 0.50 \mathrm{ng} / \mathrm{ml})$ and 42 days $(1.95 \pm 0.435 \mathrm{ng} / \mathrm{ml})$. In adulthood, from 63-to-70 days of age, testosterone values leveled out at $2.32 \pm$ $0.126 \mathrm{ng} / \mathrm{ml}$.

\subsection{Histological Growth of the Penile Spines}

The growth and development of the penile spines was characterized by a gradual differentiation of the epidermic cells in the penile epithelium (PE). As Figure 2(A) shows, at 7 postnatal days in the PE only a germinative layer (Ger) composed of cuboidal or cylindrical cells was visible. At 14 days, the germinative layer presented greater cellular proliferation that produced aggregates (called penile follicles, PF) of cuboidal cells all along the PE (Figure 2(B)). The PF were more evident on day 21;
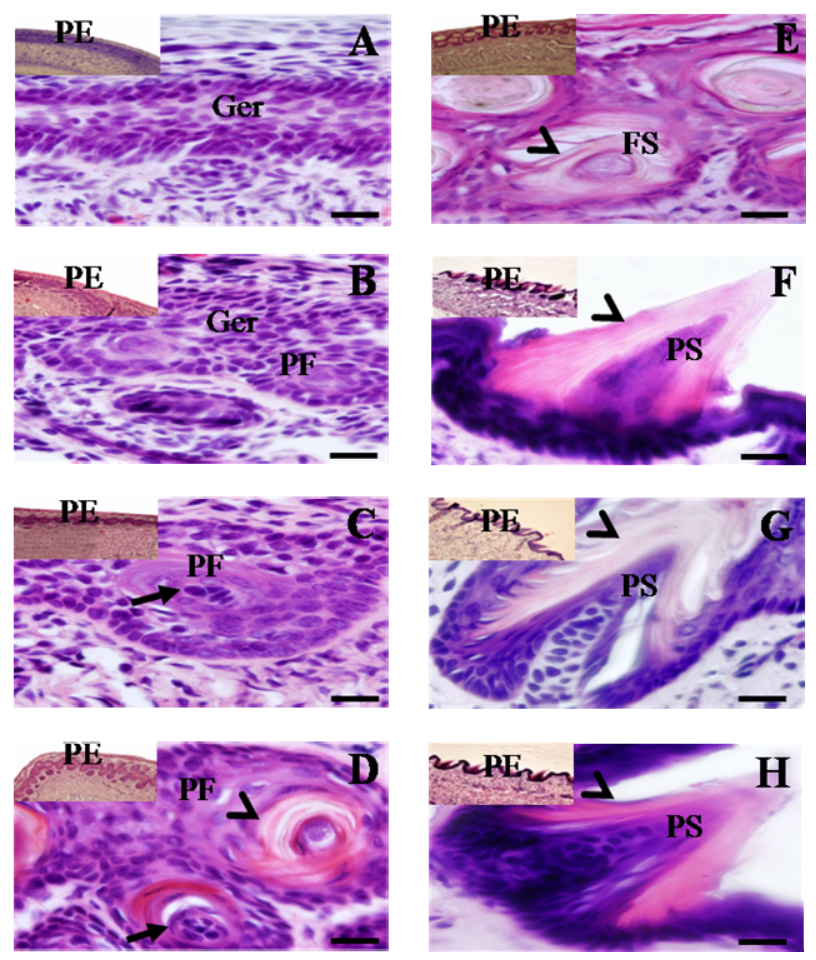

Figure 2. Histological longitudinal-sections of penile epithelium (PE) $(10 \times$ and $60 \times)$ obtained from 7 - 56 postnatal days in male rats. Note the presence of a germinative layer (Ger) on day 7 (A) and the presence of the penile follicles (PF) with granules of keratohyalin in the spindle cells (arrow) on days 14 (B); 21 (C) and 28 (D). By day 28 (D); 35 (E) and 42 (F), keratin layers (arrowheads) were visible in both the $P F$ and the penile spines (PS). Note the evident protrusion of the cone-shaped PS on day $42(F)$. The protrusion of PS continued on days 49 (G) and $56(\mathrm{H})$; with a more pronounced conical form of the PS and the presence of various layers of keratin on the ensuing days (arrowheads). Scale bar $20 \mu \mathrm{m}$. however, the cells appeared to be clearer and flatter and the presence of basophilic granules of keratohyalin was detected in the spindle cells (Figure 2(C)). At 28 days of age, the PF cells became flatter, approached the superficial area of the epidermis, and were observable in the interior of the keratin layers of the PF, where they constitute a stratum called pre-spinous (Figure 2(D)). At 35 days, this pre-spinous stratum made up of PF was detected closer to the periphery of the PE, and the PF were seen to begin to take on a conical form (Figure 2(E)). By 42 days, protrusion of the penile spines (PS) towards the periphery of the PE was visible, consisting of several layers of keratin (Figure 2(F)). By days 49 and 56, the process of the protrusion of the PS continued, and the conical form characteristic of a corneal stratum was more pronounced with a high degree of keratinization. Immediately below these keratin layers various flattened cells were observed (Figures 2(G) and (H)). These same histological characteristics in the PE were observed up to days 63 and 70 of postnatal life.

With respect to the number of PF and PS found on different days, the results are presented in Figure 3. In gen eral, the density of the PF and PS was greater in the distal portion of the penis, though their distribution varied significantly at different moments of postnatal growth $[\mathrm{F}(36,407)=447.39, \mathrm{p}<0.001]$. The presence of PF was observed for the first time at 14 days of age. Primarily in the distal portion, they attained their maximum expression at 28 days $(93.08 \pm 5.50, \mathrm{p}<0.01)$, followed by a

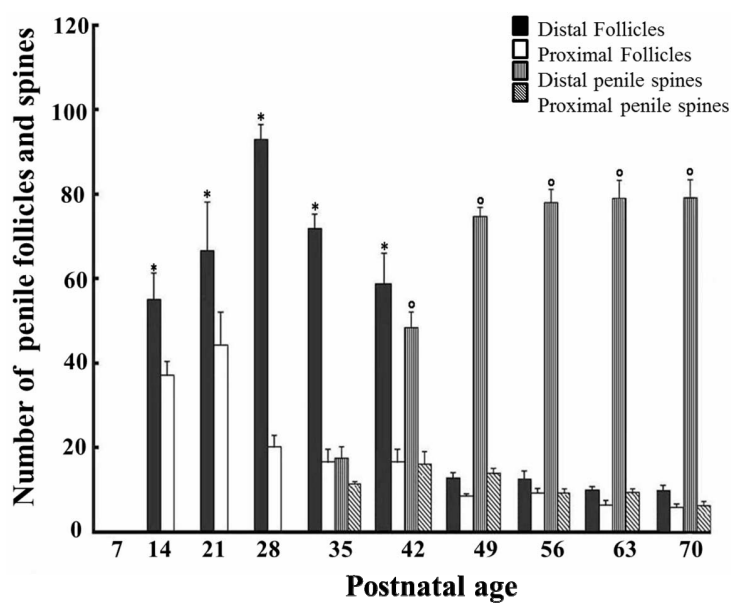

Figure 3. Number of penile follicles and spines counted at different days of age in male rats. Note the lack of penile follicles on day 7 but their gradual increase, mostly in the distal portion, at 21 and 28 postnatal days, followed by an evident decrease from 49 - 70 days. The penile spines, in contrast, showed a significant increase from days 42 - 49 and maintained a high number in the following postnatal days, also mainly in the distal portion. "p $<0.01$ as compared to the 7 th postnatal day; $p<0.01$ as compared to the 35th postnatal day (ANOVA, followed by Tukey exact probability test). 
gradual decrease. They then remained at lower levels from days 49 -to-70 $(12.83 \pm 1.85 ; 6.42 \pm 1.62, \mathrm{p}<0.01$, respectively). With respect to the PS, fewer were counted at 35 days in both the distal $(71.75 \pm 5.13)$ and proximal $(16.0 \pm 4.90)$ portions of the penis; however, after 42 postnatal days an evident increase in the number of PS, mainly in the distal portion, was observed and continued until 70 days of age.

\subsection{Histological Growth of Testicular Tissue}

The gradual postnatal growth of testicular tissue is shown in Table 1, while Figure 4 presents the histological changes observed in the seminiferous tubules (ST). Based on the tubular morphology method, which takes into account the localization and shape of spermatid nu-
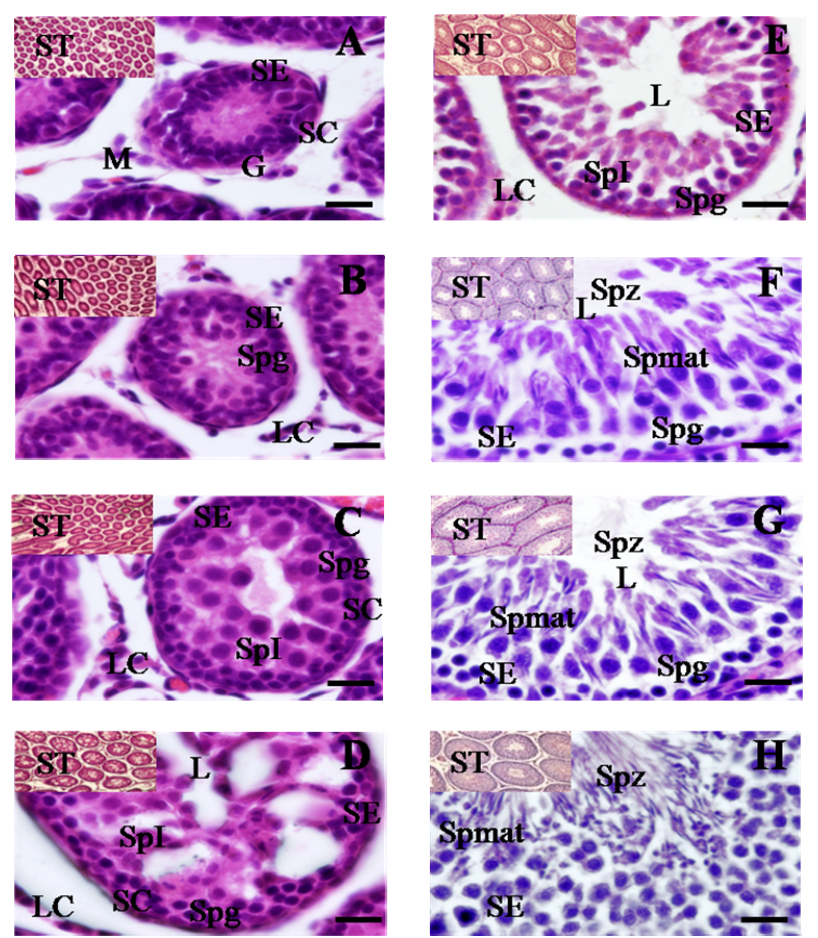

Figure 4. Histological cross-sections of testicular tissue (10× and $60 \times$ ) obtained from 7 - 56 postnatal days in male rats. At 7 days (A); seminiferous tubules (ST) were observed as solid cords without central lumen. Gonocytes $(G)$ were the only type of germ cell detected in the seminiferous epithelium (SE), surrounded by Sertoli cells (SC). Mesenchymal cells $(\mathrm{M})$ were seen in the interstitium. Spermatogonias (Spg) were identified on day 14 (B); primary spermatocytes (SpI) were first observed on day 21 in the SE, with greater quantities of $L C$ in the interstitium (C); A central lumen was observed more defined at 28 days (D); The area of SE increased at 35 days and a central lumen was totally evident. Moreover, Spg and SpI in the SE and LC were identified in the interstitium (E); Elongated spermatids (Spmat) and the release of spermatozoids (Spz) in the lumen were both observed at 42 days of age $(F)$; and these characteristics were maintained at 49 and 56 days (G) (H); Scale bar $20 \mu \mathrm{m}$. clei, the presence of meiotic divisions, and the overall composition seminiferous epithelium [34], eight stages of the spermatogenic cycle were identified. At 7 days of age, seminiferous cords sheathed by a thin tunic (which contains the peritubular myoid cells) were observed. These cords without lumen were characterized by the presence of a seminiferous epithelium (SE) that held around four layers with gonocytes (G) and Sertoli cells (SC) situated close to the basal lamina. At that age, only mesenchymal cells (M, which give rise to Leydig cells) were observed in the interstitium (Figure 4(A)). At 14 days, more abundant spermatogonias (Spg) were observed in the SE. The presence of Leydig cells (LC) was also evident in the interstitium (Figure 4(B)). At 21 postnatal days, the ST show showed abundant Spg, and the presence of SC was noted near the basal membrane. Also, primary spermatocytes $(\mathrm{SpI})$ were seen in the medial area of the SE with a higher quantity of LC in the interstitium and central lumen was evident at the first time in some tubules (Figure 4(C)). These characteristics are specific to stage I of the spermatogenic cycle. With respect to the area of the ST, a significant increase was observed through the different ages of postnatal development [F(9.211) = $363.90(p<0.001)]$. Hence, on day 21 of postnatal life, the area of ST was significantly greater (9059.15 \pm $1358.71 \mu^{2}$ ) than at day 7 (Table 1). At 28 days of age a central lumen was more evident in many tubules and its relative volume increased with age, while in the seminiferous epithelium Spg, SC and SpI were still observable, as were LC in the interstitium (Figure 4(D)). At 35 days, complete formation of the lumen of the tubule was attained in almost all tubules, so that characteristics associated with stages II and III of the spermatogenic cycle were detected together with abundant LC in the interstitium (Figure $\mathbf{4}(\mathbf{E})$ ). By 42 days of age, elongated spermatids arranged in bundles and deeply encrusted in the SE were observed, as well as abundant secondary spermatocytes located very close to the lumen of the ST and, for the first time, spermatozoids (Spz) in the lumen of the seminiferous tubules. Also present were numerous Spg among the Sertoli and Leydig cells in the interstitium (Figure 4(F)); all of which correspond to stages IV-to-VII of the spermatogenic cycle and, therefore, demonstrate that several generations of superimposed germinal cells that occur with cyclical regularity can be present simultaneously in a section of a seminiferous tubule. Also at this age, the area of the seminiferous tubules showed a significant increase $(p<0.001)$ when compared to the previous days (Table 1). At 49 days, observations showed the same components in the SE as on day 42; however, the presence of Spz was greater in the lumen of the seminiferous tubule, and there were abundant LC in the interstitium; findings that reflect stages V-to-VII of the spermatogenic cycle (Figure 4(G)). 
Upon reaching 56 days of age, the disposition of elongated Spmat on the luminal surface and the emergence of numerous large residual bodies and spermatozoids in the lumen of the seminiferous tubule (Figure 4(H)) marked stage VIII of the spermatogenic cycle. The area of the seminiferous tubules continued to expand such that significant differences were obtained $(\mathrm{p}<0.01)$ compared to previous days (Table 1). On the ensuing days of postnatal life (63-to-70), the same morphological and histological characteristics observed at 56 days of age were maintained.

\section{Discussion}

In this study, a detailed longitudinal analysis made it possible to demonstrate that the penile spines, like the testicular tissue, follow a pattern of postnatal development characterized by specific morphological changes associated with gradual increases in plasma testosterone levels.

Although the morphological characteristics of the penile epithelium [27] and its dependence on androgen levels has been described [15,17,21], because most of that research focused on specific ages of the adult rat, the precise development pattern of these penile structures had not yet been determined. Thus, to the best of our knowledge, this is the first study to specifically describe the morphological changes that occur in the penile epithelium of the postnatal male rat.

The data from this study show a close temporal association between gradual increases in testosterone levels and the progressive growth of the follicles until they form penile spines with a high degree of keratinization. From 7 - 28 days of age, a slight increase in testosterone levels was detected, though it did not reach statistical significance. That period was characterized only by the presence of follicles located mainly in the distal portion of the epithelium of the penis. However, at around 42 days of age, higher levels of testosterone $(2.0 \mathrm{ng} / \mathrm{ml})$ were detected in association with the early protrusion of the penile spines, primarily in the distal portion. Testosterone levels continued to increase with age, reaching their maximum value on day $70(2.33 \mathrm{ng} / \mathrm{ml})$, a finding that correlated with the highest number of protruded penile spines in the gland. Similar testosterone levels have been found in Wistar rats at 90 days $(2.5 \mathrm{ng} / \mathrm{ml})$ in basal conditions [35]. Thus, these data support the notion that penile spine growth is dependent on the gradual increase of testosterone levels during the first days of life in male rats.

These results agree with data reported by Vilamaior et al. [4] who, using the chemiluminescence immunoassay method, observed a gradual increase in testosterone levels throughout the postnatal stage in Wistar male rats. They reported a first peak at 42 days $(1.5-2.0 \mathrm{ng} / \mathrm{ml})$ and a maximum level at day $70(3.5 \mathrm{ng} / \mathrm{ml})$, as in our study. Sachs and Meisel in 1979 [9] also reported increasing testosterone levels after 25 postnatal days that reached values as high as $9.26 \mathrm{ng} / \mathrm{ml}$ at 50 days, and 6.17 $\mathrm{ng} / \mathrm{ml}$ at 60 days. Such elevated testosterone values were not detected in the present study, in which the maximum level found reached a mean value of only $2.3 \mathrm{ng} / \mathrm{ml}$ on day 70 . The differences between the results obtained by Sachs and Meisel [9] and those reported here may be attributable to three factors: the different methods used in the respective studies (i.e., RIA vs. HPLC with ultraviolet detection); differences in the rat strains used in the respective experiments (Long Evans vs. Wistar); or differences in the experimental conditions.

Our data, like the results reported by Dorostghoal et al. [5], support the notion that in the male Wistar rat the process of puberty begins between 35 and 42 days of age with the appearance of elongated spermatids and the release of spermatozoids into the tubule lumen. It has been reported that in accordance with the postnatal growth of their sexual organs male rats also show certain behavioral acts related to sexual maturation, such as genital self-grooming and penile erections. Around 35-to-44 days, precisely upon reaching puberty, male rat pups show an obvious increase in genital self-grooming and the frequency of spontaneous penile erections, phenomena that have been linked to the pubertal growth of the prostate gland, seminal vesicles and testes in juvenile rats [36].

It has been suggested, that intromission and ejaculation responses in rats cannot occur until the male's penis is eversible from its surrounding sheath [37]. Testosterone stimulates the cornification of the epithelial cells that connect the penis to its sheath in a process that eventually leads to preputial sheath separation. Various authors $[8,9,38,39]$ have demonstrated that separation of the sheath occurs at $44-45$ days of age, while recent data from our laboratory indicate that this event occurs sometime after the 41st day of life in Wistar rats (unpublished data). Thus, the results of our study agree with the notion that increased testosterone levels constitute an important factor in the maturation process of penile tissue and its association with the performance of genital self-grooming and spontaneous penile erection, all of which, as has been suggested, are regulated by hormonal levels and contribute to readying the adult male rat for reproduction [40]. The critical role of testosterone in the maturation of the penile spines has been confirmed in several studies. Penile spines are androgen-dependent structures that are lost upon castration, but recovered after treatment with exogenous testosterone $[25,20]$. Atrophy of the penile spine in castrated rats decreases the tactile sensitivity of the glans and contributes to a reduction in male sexual behavior. Moreover, the penile spines play a fundamental 
role in stimulating the vagina during copulation and in removing the sperm of competitors [19,20,41].

With respect to the pattern of testicular growth during postnatal development, as expected, both testicular weight and the area of the seminiferous tubules increased progressively with age, with morphological changes in the germ cells that were associated with the gradual increase in testosterone levels. Data from our study show a marked concordance with the results obtained by other authors $[5,28,29]$. As has been reported previously, at birth the seminiferous tubules were seen as a solid cord with gonocytes present in the center but without a central lumen. This condition first became evident at 28 days of age in some tubules and complete formation of the lumen of the tubule was showed at 35 days. These data agree with those reported by Dorostghoal et al. [5] who, through a detailed stereological analysis of the testes, reported a similar age for the formation of the tubular lumen, though the presence of primary spermatocytes was determined at 14 days of age. In our study, the presence of primary spermatocytes was not observed until 21 days of age; however, as in Dorostghoal's work, the appearance of elongated spermatids and the presence of spermatozoa were observed in the tubular lumen between 35 and 42 days. Interestingly, these findings coincide with substantial growth in the area of the seminiferous tubules and a notable increase in testosterone levels that reached their first peak on those same days.

It is well known that testosterone plays a preponderant role in spermatogenesis, specifically in the conversion of round spermatids to the elongated form $[10,11]$. Our data agree with these facts since the increase in testosterone levels observed between 35 and 42 days of age can be associated with the presence of elongated spermatids at 42 days. Moreover, although the germ cells do not have androgen receptors [42], it has been suggested that testosterone may regulate spermatogenesis through expression of the androgen receptors localized in the Sertoli cells, the peritubular myoid cells and the Leydig cells [12].

Although these data demonstrated a close relation between development of the penile and testicular tissues and testosterone levels, it is important to consider that the effects of testosterone depend on the production of active metabolites such as $5 \alpha$-dihydrotestosterone and $17 \beta$-estradiol [43], as well as on indirect effects mediated by several mechanisms, including changes in the level of other endocrine hormones, such as Growth Hormone $(\mathrm{GH})$, androgen-induced changes in the secondary transcription regulators, and the secretion of autocrine or paracrine regulators [44].

Finally, with respect to body weight and testosterone levels during postnatal development, both aspects showed a progressive increase with age. Some studies have suggested that testosterone regulates muscle mass during development and regeneration in animal models $[45,46]$ particularly in the levator ani muscle [47]; however, other research has reported inconsistent data concerning the effects of testosterone on the proliferation and differentiation of myogenic cells [48,49]. Therefore, it is difficult to conclude that there is a direct correlation between body weight and increased testosterone levels in relation to age.

\section{Conclusions}

The present data demonstrated an important temporal coincidence between the developmental pattern of penile spines and testicular tissue and plasma testosterone levels; these findings may improve our understanding of the functional changes that take place in the testes and penile tissue during early life, and serve as a useful reference for future research.

Finally, our study emphasized the importance of considering the close relationship between morphological changes in the sexual organs and testosterone levels when conducting experiments designed to assess the effects of diverse experimental or pharmacological manipulations on juvenile male Wistar rats.

\section{Acknowledgements}

The authors would like to thank Pedro Medina Granados of the Instituto Nacional de Pediatría for his technical support and assistance.

\section{REFERENCES}

[1] F. W. George and J. D. Wilson, "Sex Determination and Differentiation," In: E. Knobil and J. Neil, Eds., Physiology of Reproduction, 2nd Edition, Raven Press, New York, 1994, pp. 3-28.

[2] R. S. Ge, L. X. Shan and M. P. Hardy, "Pubertal Development of Leydig Cells," In: D. Lussell, Ed., The Leydig Cell, River Press, Vienna, 1996, pp. 159-173.

[3] R. S. Ge, Q. Dong, C. M. Sottas, H. Chen, B. R. Zirkin and M. P. Hardy, "Gene Expression in Rat Leydig Cells during Development from the Progenitor to Adult Stage: A Cluster Analysis," Biology of Reproduction, Vol. 72, No. 6, 2005, pp. 1405-1415. doi:10.1095/biolreprod.104.037499

[4] P. S. Vilamaior, S. R. Taboga and H. F. Carvalho, "Postnatal Growth of the Ventral Prostate in Wistar Rats: A Stereological and Morphometrical Study," The Anatomical Record Part A: Discoveries and Molecular, Cellular, and Evolution Biology, Vol. 288A, No. 8, 2006, pp. 885892. doi:10.1002/ar.a.20363

[5] M. Dorostghoal, F. Sorooshnia and A. Zardkaf, "Stereological Analysis of Wistar Rat Testis during Early PostNatal Development," Anatomia, Histologia Embryologia, Vol. 40, No. 2, 2011, pp. 89-94. 


\section{doi:10.1111/j.1439-0264.2010.01043.x}

[6] C. A. Anderson and R. L. Clark, "External Genitalia of the Rat: Normal Development and the Histogenesis of 5a-Reductase Inhibitor-Induced Abnormalities," Teratology, Vol. 42, No. 5, 1990, pp. 483-496. doi:10.1002/tera.1420420505

[7] C. A. Wilson and D. C. Davies, "The Control of Sexual Differentiation of the Reproductive System and Brain," Reproduction, Vol. 133, No. 2, 2007, pp. 331-359. doi:10.1530/REP-06-0078

[8] C. C. Korenbrot, I. T. Huhtaniemi and R. I. Weiner, "Preputial Separation as an External Sign of Pubertal Development in the Male Rat," Biology of Reproduction, Vol. 17, No. 2, 1977, pp. 298-303. doi:10.1095/biolreprod17.2.298

[9] B. D. Sachs and R. L. Meisel, "Pubertal Development of Penile Reflexes and Copulation in Male Rats," Psychoneuroendocrinology, Vol. 4, No. 4, 1979, pp. 287-296. doi:10.1016/0306-4530(79)90013-1

[10] L. O'Donnell, R. I. McLachlan, N. G. Wreford and D. M. Robertson, "Testosterone Promotes the Conversion of Round Spermatids between Stages Vll-Vlll of the Rat Spermatogenic Cycle," Endocrinology, Vol. 135, No. 6, 1994, pp. 2608-2614. doi:10.1210/en.135.6.2608

[11] N. Sofikitis, K. Ono, Y. Yamamoto, H. Papadopoulosand and I. Miyagawa, "Influence of the Male Reproductive Tract on the Reproductive Potential of Round Spermatids Abnormally Released from the Seminiferous Epithelium," Human Reproduction, Vol. 14, No. 8, 1999, pp. 19982006. doi:10.1093/humrep/14.8.1998

[12] M. Welsh, R. M. Sharpe, M. Walker, L. B. Smith and P. T. Saunders, "New Insights into the Role of Androgens in Wolffian Duct Stabilization in Male and Female Rodents," Endocrinology, Vol. 150, No. 5, 2009, pp. 2472-2480. doi:10.1210/en.2008-0529

[13] M, Arteaga Silva, R. M. Vigueras Villaseñor, S. Retana Márquez, M. Hernández González, C. Chihuahua Serrano, H, Bonilla-Jaime, J. L. Contreras and G. Moralí, "Testosterone, Androstenedione, and 5alpha-Dihydrotestosterone on Male Sexual Behavior and Penile Spines in the Hamster," Journal Physiology and Behavior, Vol. 94, No. 3, 2008, pp. 412-421.

[14] H. Kanagawa and E. S. Hafez, "The Penis," In: E. S. Hafez, Ed., Scanning Electron Microscopic Atlas of Mammalian Reproduction, Thieme, Stuttgart, 1975.

[15] G. T. Taylor, D, Komitowski and J. Weiss, "Light and Scanning Electron Microscopic Study of TestosteroneRestored Penile Papillae in Castrated Rats," Journal Anatomical Records, Vol. 205, No. 3, 1983, pp. 277-286. doi:10.1002/ar.1092050305

[16] G.T. Taylor, J. Weissand and D. Komitowski, "Reproductive Physiology and Penile Papillae Morphology of Rats after Sexual Experience," Journal of Endocrinology, Vol. 98, No. 3, 1983, pp. 155-163. doi:10.1677/joe.0.0980155

[17] B. D. Sachs, G. B. Glater and J. K. O’Hanlon, "Morphology of the Erect Glans Penis in Rats under Various Gonadal Hormone Conditions," The Anatomical Records, Vol. 210, No. 1, 1984, pp. 45-52.

\section{doi:10.1002/ar.1092100108}

[18] R. Murakami. "A Histological Study of the Development of the Penis of Wild-Type and Androgen-Insensitive Mice," Journal of Anatonomy, Vol. 153, 1987, pp. 223231.

[19] B. D. Sachs, "Role of Striated Penile Muscles in Penile Reflexes, Copulation, and Induction of Pregnancy in the Rat," Journal of Reproduction and Fertility, Vol. 66, No. 2, 1982, pp. 433-443. doi:10.1530/jrf.0.0660433

[20] J. K. O'Hanlonand and B. D. Sachs, "Fertility of Mating in Rats (Rattusnorvegicus): Contributions of AndrogenDependent Morphology and Actions of the Penis," Journal of Comparative Psychology, Vol. 100, No. 2, 1986, pp. 178-187. doi:10.1037/0735-7036.100.2.178

[21] N. C. Kierniesky and A. A. Gerall, "Effects of Testosterone Propionate Implants in the Brain on the Sexual Behavior and Peripheral Tissue of the Male Rat," Journal Physiology and Behavior, Vol. 11, No. 5, 1973, pp. 633640. doi:10.1016/0031-9384(73)90248-5

[22] M. J. Baum, S. A. Tobet, M. S. Starr and W. G. Bradshaw, "Implantation of Dihydrotestosterone Propionate into the Lateral Septum or Medial Amygdale Facilitates Copulation in Castrated Mate Rats Given Estradiol Systemically," Hormones and Behavior, Vol. 16, No. 2, 1982, pp. 208-223. doi:10.1016/0018-506X(82)90020-4

[23] C. H. Phoenix, K. H. Copenhaver and R. M. Brenner, "Scanning Electron Microscopy of Penile Papillae in Intact and Castrated Rats," Hormones and Behavior, Vol. 7, No. 2, 1976, pp. 217-227. doi:10.1016/0018-506X(76)90049-0

[24] F. A. Beach and L. P. Nucci, "Long-Term Effects of Testosterone Phenyl Acetate on Sexual Morphology and Behavior in Castrated Male Rats," Hormones and Behavior, Vol. 1, No. 1, 1970, pp. 223-234. doi:10.1016/0018-506X(70)90016-4

[25] H. H. Feder, "The Comparative Actions of Testosterone and $5 \alpha$-Androstan-17 $\beta$-ol-3-One Propionate on the Reproductive Behavior, Physiology, and Morphology of Male Rats," The Journal of Endocrinology, Vol. 51, No. 2, 1971, pp. 241-252. doi:10.1677/joe.0.0510241

[26] D. M. Kretser and J. B. Kerr. "The Cytology of the Testis," In: E. Knobil and J. Neil, Eds., Physiology of Reproduction, 2nd Edition, Raven Press, New York, 1994, pp. 1177-1290.

[27] R. D. Johnson and Z. Halata, "Topography and Ultrastructure of Sensory Nerve Endings in the Glans Penis of the Rat," The Journal of Comparative Neurology, Vol. 312, No. 2, 1991, pp. 299-310. doi:10.1002/cne.903120212

[28] H. Mori and A. K. Christensen, "Morphometric Analysis of Leydig Cells in the Normal Rat Testis," Journal of Cell Biology, Vol. 84. No. 2, 1982, pp. 340-354. doi:10.1083/jcb.84.2.340

[29] T. Y. Wing and A. K. Christensen, "Morphometric Studies on Rat Seminiferous Tubules," Annals Journal of Anatomy, Vol. 165, No. 1, 1982, pp. 13-25.

[30] F. Gaytan, M. Concepcion, L. E. Muñoz and R. Paniagua, "Morphometric Aspects of Rat Testis Development," 
Journal of Anatomy, Vol. 145, 1996, pp. 155-159.

[31] Y. N. Zhengwei, G. Wreford and D. M. de Kretser, "A Quantitative Study of Spermatogenesis in the Developing Rat Testis," Biology of Reproduction, Vol. 43, No. 4, 1990, pp. 629-635. doi:10.1095/biolreprod43.4.629

[32] I. S. Kim and H. H. Yang, "Morphometric Study of the Testicular Interstitium of the Rat during Postnatal Development," Korean Journal Anatomy, Vol. 32, No. 6, 1999 , pp. 849-858.

[33] C. Woodward and P. Emery, "Determination of Plasma Corticosterone Using High Performance Liquid Chromatography," Journal of Chromatography, Vol. 419, 1987, pp. 280-284.

[34] W. E. Berndtson, "Methods for Quantifying Mammalian Spermatogenesis: A Review," Journal of Animal Science, Vol. 44, No. 5, 1977, pp. 818-833.

[35] H. Bonilla-Jaime, G. Vázquez-Palacios, M. Arteaga-Silva and S. Retana-Márquez, "Hormonal Responses to Different Sexually Related Conditions in Male Rats," Hormones and Behavior, Vol. 49, No. 3, 2006, pp. 376- 382. doi:10.1016/j.yhbeh.2005.08.005

[36] C. L. Moore and S. A. Rogers, "Contribution of SelfGrooming to the Onset of Puberty in Male Rats," Developmental Psychobiology, Vol. 17, No. 3, 1984, pp. 243253.

[37] C. P. Stone, "The Awakening of Copulatory Ability in the Male Albino Rat," American Journal of Physiology, Vol. 68, 1924, pp. 407-424.

[38] M. Hernández-González, "Prepubertal Genital Grooming and Penile Erections in Relation to the Sexual Behavior of Rats," Journal Physiology and Behavior, Vol. 71, No. 1-2, 2000, pp. 51-56. doi:10.1016/S0031-9384(00)00320-6

[39] M. Hernández-González, K. E. Sánchez, M. V. Blando, S. Orozco-Suarez, M. Arteaga-Silva and M. A. Guevara, "Effects of Alcohol on Behavioral and Morphologic Indices of Sexual Maturation in Male Rats," Alcohol, Vol. 33, No. 2, 2004, pp. 117-126. doi:10.1016/j.alcohol.2004.06.002

[40] C. L. Moore, "Sex Differences in Self-Grooming of Rats: Effects of Gonadal Hormones and Context," Journal Physiology and Behavior, Vol. 36, No, 3, 1986, pp. 451455. doi:10.1016/0031-9384(86)90314-8

[41] M. N. Simmons and J. S. Jones, "Male Genital Morphology and Function: An Evolutionary Perspective," The Journal of Urology, Vol. 177, No. 5, 2007, pp. 1625-1631. doi:10.1016/j.juro.2007.01.011

[42] D. S. Johnston, L. D. Russell, P. J. Friel and M. D. Griswold, "Murine Germ Cells Do Not Require Functional Androgen Receptors to Complete Spermatogenesis Following Spermatogonial Stem Cell Transplantation," Endocrinology, Vol. 142, No. 6, 2001, pp. 2405-2408. doi:10.1210/en.142.6.2405

[43] J. D. Wilson. "Metabolism of Testicular Androgens," In: D. W. Hamilton and R. O. Greep, Eds., Handbook of Physiology, Williams and Wilkins Co., Baltimore, 1975, pp. 143-172.

[44] H. E. MacLean, W. S. Chiu, A.J. Notini, A. M. Axell, R. A. Davey, J. F. McManus, C. Ma, D. R. Plant, G. S. Lynch and J. D. Zajac, "Impaired Skeletal Muscle Development and Function in Male, But Not Female, Genomic Androgen Receptor Knockout Mice," FASEB Journal: Official Publication of the Federation of American Societies for Experimental Biology, Vol. 22, No. 8, 2008, pp. 2676-2689.

[45] Ophoff, K. Van Proeyen, F. Callewaert, K. De Gendt, K. De Bock, A. Vanden Bosch, G. Verhoeven, P. Hespel, and D. Vanderschueren, "Androgen Signaling in Myocytes Contributes to the Maintenance of Muscle Mass and Fiber Type Regulation But Not to Muscle Strength or Fatigue," Endocrinology, Vol. 150, No. 8, 2009, pp. 35583566. doi:10.1210/en.2008-1509

[46] D. K. Lee, “Androgen Receptor Enhances Myogenin Expression and Accelerates Differentiation," Biochemical and Biophysical Research Communications, Vol. 294, No. 2, 2002, pp. 408-413. doi:10.1016/S0006-291X(02)00504-1

[47] Y. Joubert, C. Tobin and M. C. Lebart, "TestosteroneInduced Masculinization of the Rat Levator Ani Muscle during Puberty," Developmental Biology, Vol. 162, No. 1, 1994, pp. 104-110. doi:10.1006/dbio.1994.1070

[48] P. Diel, D. Baadners, K. Schlüpmann, M. Velders and J. P. Schwarz, "C2C12 myoblastoma Cell Differentiation and Proliferation Is Stimulated by Androgens and Associated with a Modulation of Myostatin and Pax7 Expression," Journal of Moecularl Endocrinology, Vol. 40, No. 5, 2008, pp. 231-241. doi:10.1677/JME-07-0175

[49] K. De Gendt and G. Verhoeven, "Tissue- and Cell-Specific Functions of the Androgen Receptor Revealed through Conditional Knockout Models in Mice," Molecular and Cellular Endocrinology, Vol. 352, No. 1-2, 2012, pp. 13-25. doi:10.1016/j.mce.2011.08.008 